\title{
TEMPERATURE PROFILES IN LIQUID METALS AND THE EFFECT OF SUPERIMPOSED FREE CONVECTION IN TURBULENT FLOW
}

\author{
H. O. BUHR†, A. D. CARR $†$ and R. E. BALZHISER \\ (Received 30 January 1967 and in revised form 20 June 1967)
}

\begin{abstract}
Temperature profiles measured in mercury and the NaK eutectic are reported for vertical fow in pipes under conditions of constant heat flux, and it is shown that the mercury profiles are distorted by a superimposed free convection effect up to Reynolds numbers of at least 50000 . A correlation is presented whereby the amount of distortion under given conditions may be estimated, and the shape of the undistorted temperature profile may be predicted. These profiles are used to determine the ratio of eddy diffusivities and the Nusselt number for liquid metals in the Reynolds number range $3 \times 10^{4}$ to $3 \times 10^{5}$.
\end{abstract}

\section{NOMENCLATURE}

$a, b, \quad$ constants;

$c_{p}, \quad$ specific heat $\left[\mathrm{Btu} / \mathrm{bb}^{\circ} \mathrm{F}\right]$;

$D$, pipe diameter $[\mathrm{ft}]$;

f, Fanning friction factor;

$g$, gravitational acceleration $\left[\mathrm{ft} / \mathrm{s}^{2}\right]$;

$G, \quad$ mass flow rate $\left[\mathrm{lb} / \mathrm{h} \mathrm{ft}^{2}\right]$;

Gr, Grashof number,

$G r^{*}, \quad$ Grashof number, $D^{3} \rho^{2} \beta g(\mathrm{~d} T / \mathrm{d} x) D / \mu^{2}$, used in the parameter $Z$;

$h$ heat-transfer coefficient $\left[\mathrm{Btu} / \mathrm{hft}^{2}{ }^{\circ} \mathrm{F}\right]$

$k$, thermal conductivity $\left[\mathrm{Btu} / \mathrm{h} \mathrm{ft}{ }^{\circ} \mathrm{F}\right]$;

$L$, length of test section from inlet to measuring position $[\mathrm{ft}]$;

$N u, \quad$ Nusselt number, $h D / k$;

$P e, \quad$ Péclet number, $=\operatorname{Pr} \times \operatorname{Re}$;

$P r, \quad$ Prandtl number, $c_{p} \mu / k$;

$q_{w}$, heat flux at wall $\left[\mathrm{Btu} / \mathrm{h} \mathrm{ft}^{2}\right]$;

$r$ radial distance measured from pipe centre $[\mathrm{ft}]$;

$\dagger$ Department of Chemical Engineering, University of Cape Town, South Africa.

$\ddagger$ Department of Chemical and Metallurgical Engineering, University of Michigan, U.S.A.
$R, \quad$ radius of pipe [ft];

$\mathrm{Ra}, \quad$ Rayleigh number, $\mathrm{Gr}^{*} \times \mathrm{Pr}$;

$R e, \quad$ Reynolds number, $D G / \mu$;

$S, \quad$ slope of temperature profile, $\mathrm{d} T / \mathrm{d} y$ $\left[{ }^{\circ} \mathrm{F} / \mathrm{ft}\right]$;

$S_{0}, \quad$ slope at the wall $\left[{ }^{\circ} \mathrm{F} / \mathrm{ft}\right]$;

$S_{y}, \quad$ slope at position $y\left[{ }^{\circ} \mathrm{F} / \mathrm{ft}\right]$;

$T$, temperature $\left[{ }^{\circ} \mathrm{F}\right]$;

$T_{a v} \quad$ mean cup temperature $\left[{ }^{\circ} \mathrm{F}\right]$;

$T_{c}, \quad$ temperature at pipe centre $\left[{ }^{\circ} \mathrm{F}\right]$;

$T_{w}, \quad$ wall temperature $\left[{ }^{\circ} \mathrm{F}\right]$;

$u$, velocity $[\mathrm{ft} / \mathrm{s}]$;

$u_{a v}, \quad$ mean velocity $[\mathrm{ft} / \mathrm{s}]$;

$u^{*}, \quad$ friction velocity $[\mathrm{ft} / \mathrm{s}]$;

$x, \quad$ axial distance $[\mathrm{ft}]$;

$y$, radial distance measured from wall [ft];

$Y$, Yantovskii criterion, $G r / R e^{2}(f / 2)$;

$Z, \quad$ correlating parameter, $R a(D / L) / R e$.

Greek symbols

$\begin{array}{ll}\alpha, & \text { thermal diffusivity, } k / \rho c_{p}\left[\mathrm{ft}^{2} / \mathrm{h}\right] ; \\ \beta, & \text { coefficient of thermal expansion } \\ & {\left[{ }^{\circ} \mathrm{F}^{-1}\right] ;} \\ \epsilon_{H}, & \text { eddy diffusivity of heat }\left[\mathrm{ft}^{2} / \mathrm{h}\right] ; \\ \epsilon_{M}, & \text { eddy diffusivity of momentum } \\ \mu, & {\left[\mathrm{ft}^{2} / \mathrm{h}\right] ;} \\ & \text { viscosity }[\mathrm{lb} / \mathrm{fth}] ;\end{array}$




\author{
$\rho, \quad$ density $\left[\mathrm{lb} / \mathrm{ft}^{3}\right]$; \\ $\phi(y / R)$, heat flux distribution according to \\ equation (8); \\ $\psi, \quad$ eddy diffusivity ratio, $\epsilon_{H} / \epsilon_{M}$.
}

\section{INTRODUCTION}

THE FIRST heat-transfer theory specifically applicable to liquid metals was put forward in 1947 by Martinelli [1], who recognised that, for these fluids, molecular conduction of heat in the turbulent core would be significant in comparison with eddy diffusion. Martinelli also noted that the ratio of eddy diffusivities of heat and momentum would not necessarily be equal, as assumed in earlier heat-transfer analogies. In 1951 Lyon [2], following similar reasoning, presented the simple approximate equation

$$
N u=7+0.025(\psi P e)^{0 \cdot 8}
$$

for the case of constant heat flux through the tube wall. This relation with $\psi$, the ratio of eddy diffusivities, equal to unity, is the wellknown Martinelli-Lyon equation. In practice it has been found that experimental Nusselt numbers, particularly for the heavy metals, generally fall 20-30 per cent below the Martinelli-Lyon curve [3]. Attempts to reconcile the theory with these results have centred mainly on the two concepts of a thermal contact resistance at the tube surface, and of differences in the mechanism of heat and momentum transport. Investigation of the former indicates that the contact resistance effect is too small to account for the differences observed [4], while the latter consideration has led to a number of further heat-transfer theories [5-7]. These theories are generally based on the heat loss from an eddy, and give rise to different values of the ratio of eddy diffusivities and of the Nusselt number.

In order to investigate the validity of these theories, the eddy diffusivities $\epsilon_{H}$ and $\epsilon_{M}$ may be calculated from experimental temperature and velocity profiles. Such profiles were first measured, in mercury, by Isakoff [8] in 1952, and since then further temperature profiles have been reported [9-17] for both mercury and alkali metals, as shown in Table 1. Comparison of these profiles, however, shows that there are wide differences in the data obtained under apparently similar conditions and, as a result, it has not been possible to obtain consistent values of the ratio of eddy diffusivities [18].

In the present investigation, temperature profiles were measured in mercury and in the $\mathrm{NaK}$ eutectic in an attempt to clarify the experimental discrepancies. Consideration of these profiles, together with those of other workers, shows that the differences observed may be primarily attributed to a distorting superimposed free convection effect which, for mercury, may be appreciable for Reynolds numbers up to at least 50000 . A correlation is presented which demonstrates this effect, and also allows prediction of undistorted temperature profiles. These profiles are used to calculate values of the eddy diffusivity ratio and the Nusselt number.

\section{EQUIPMENT}

Two heat-transfer loops were used for the measurement of temperature profiles in mercury and the $\mathrm{NaK}$ eutectic respectively. The principles of construction were similar and the $\mathrm{NaK}$ loop is shown schematically in Fig. 1. Detailed descriptions have been given elsewhere $[19,20]$.

Each loop was fabricated from seamless stainless-steel tubing and contained a vertically mounted test section, dimensions of which are given in Table 2. Each test section incorporated a temperature probing station and was electrically heated by means of a carefully spaced winding of $\frac{1}{2}$-in nichrome ribbon, to give constant heat flux conditions. The return leg of each loop was water-jacketed for heat removal.

In the $\mathrm{NaK}$ apparatus, a canned-rotor pump and an electromagnetic flow meter were situated at the bottom of the loop, which was arranged so that the fluid flowed downwards through the test section. The mercury loop utilised a centrifugal pump run at low speeds and the flow in the test section was vertically upwards. 
Table 1. Liquid metal temperature profile measurements

\begin{tabular}{|c|c|c|c|c|c|}
\hline Investigator & Year & $\begin{array}{l}\text { Liquid } \\
\text { metal }\end{array}$ & $\begin{array}{c}\text { Flow } \\
\text { direction }\end{array}$ & $\begin{array}{l}\text { Number of } \\
\text { profiles } \\
\text { reported }\end{array}$ & $\operatorname{Re} \times 10^{-3}$ \\
\hline Isakoff [8] & 1952 & $\mathrm{Hg}$ & $\uparrow$ & 12 & $37 \cdot 6-373$ \\
\hline Brown et al. [9] & 1957 & $\mathrm{Hg}$ & $\uparrow \uparrow$ & 5 & $244-731$ \\
\hline Kirillov et al. [10] & 1959 & $\mathrm{NaK}(78 \% \mathrm{~K})$ & $\uparrow$ & 6 & $4 \cdot 5-36 \cdot 4$ \\
\hline Subbotin et al. [11]] & 1961 & $\mathrm{Hg}$ & $\uparrow$ & 2 & 26.9 and 288 \\
\hline \multirow{2}{*}{ Subbotin et al. [12] } & 1961 & $\mathrm{Hg}$ & $\uparrow$ & 2 & $24 \cdot 2$ and 204 \\
\hline & & $\operatorname{NaK}(78 \% \mathrm{~K})$ & $\uparrow$ & 2 & 16.2 and 24.7 \\
\hline Buyco [13] & 1961 & $\mathrm{Hg}$ & $\rightarrow$ & 5 & $55 \cdot 5-111$ \\
\hline Kokorev and Ryaposov [14] & 1962 & $\mathrm{Hg}$ & $\rightarrow$ & $\ddagger$ & $110-160$ \\
\hline Subbotin et al. [15] & 1963 & $\mathrm{Hg}$ & $\uparrow$ & $28^{+}$ & $22 \cdot 1-427$ \\
\hline Borishanskii et al. [16] & 1963 & $\mathrm{Na}$ & $\uparrow$ & 1 & $50 \cdot 7$ \\
\hline Schrock [17] & 1964 & $\operatorname{NaK}(56 \% \mathrm{~K})$ & $\rightarrow$ & $23 \S$ & $2 \cdot 1-76 \cdot 8$ \\
\hline \multirow[t]{2}{*}{ This work } & & $\mathrm{Hg}$ & $\uparrow$ & 18 & 3.8-251 \\
\hline & & $\mathrm{NaK}(78 \% \mathrm{~K})$ & $\downarrow$ & 10 & $31 \cdot 4-153$ \\
\hline
\end{tabular}

$\dagger$ Liquid metal cooled. In all other cases the test fluid was heated.

¥ These investigators do not report individual profiles. An "averaged" profile is given for three values of $R e$.

$\S$ These profiles include vertical, horizontal and $45^{\circ}$ traverses.

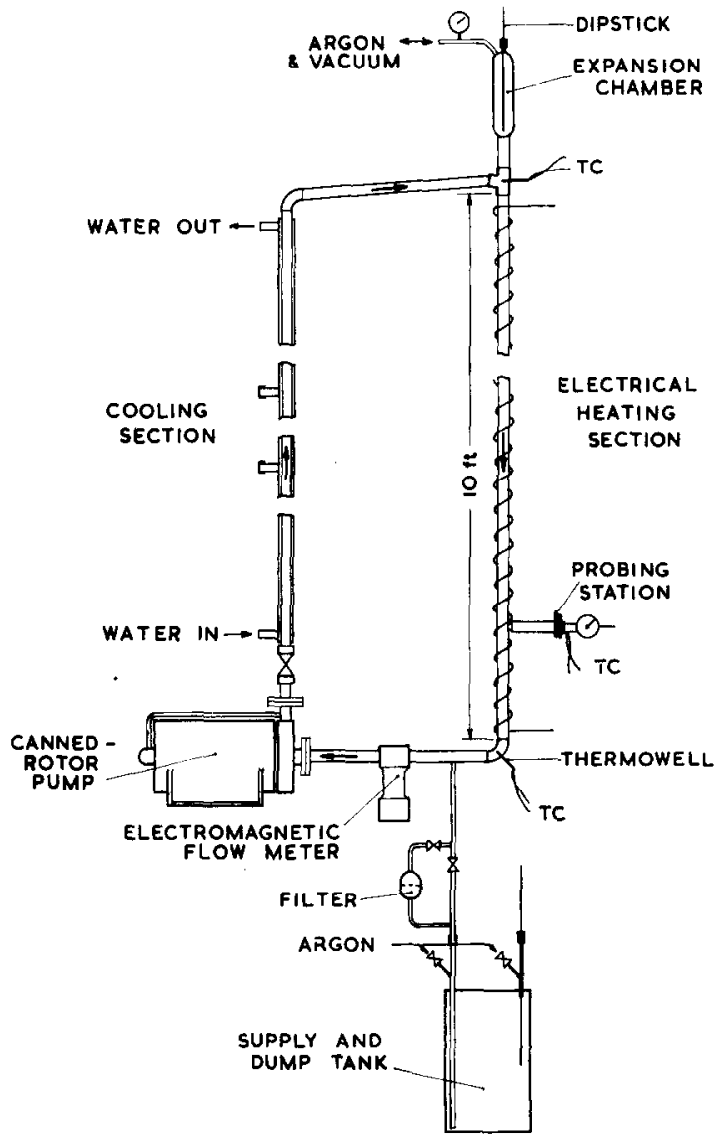

FIG 1. NaK heat-transfer loop.
This pump and an orifice meter were situated in the top section of the mercury loop in order to minimise static pressure on the pump gland and orifice meter connections. Both loops were provided with an overhead expansion chamber, which was offset from the main flow stream, to obviate the gas entrainment problems encountered by other workers.

A typical temperature probe is shown in Fig. 2, and consists of an iron-constantan thermocouple in a 0.028 in O.D. hypodermic needle, carried by a $\frac{1}{8}$-in strut. The thermocouple wires were bent slightly forward so that, on advancing the probe to the wall, the thermocouple would contact the wall first and the wall position could therefore be accurately determined by electrical contact. Traversing was achieved by a screw-thread arrangement and the position of the probe was indicated by a dial-gauge reading to 0.0002 in. In the case of the NaK probe, a thin stainless steel bellows prevented $\mathrm{NaK}$ leakage while still permitting the necessary traversing movement.

\section{RESULTS}

Temperature profiles were measured over the range of operating conditions shown in Table 


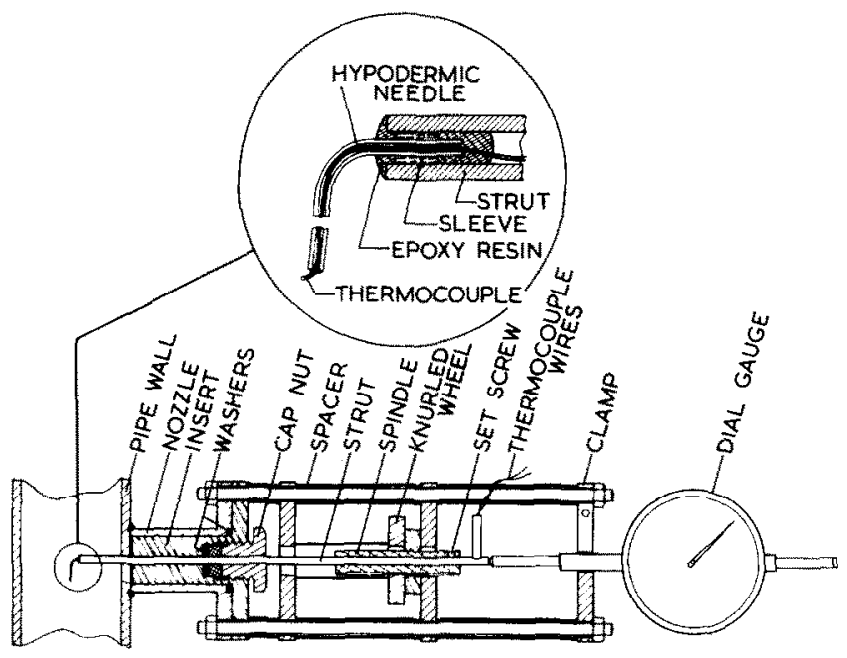

FIG. 2. Temperature probe used in mercury loop.

Table 2. Details of test section

\begin{tabular}{lcc}
\hline & Mercury loop & NaK loop \\
\hline Pipe diameter, inside & $1.624 \mathrm{in}$ & $1.380 \mathrm{in}$ \\
Wall thickness & $0.138 \mathrm{in}$ & $0.140 \mathrm{in}$ \\
Total heated length & $16.3 \mathrm{ft}$ & $10.0 \mathrm{ft}$ \\
Distance from inlet to probe & $14.2 \mathrm{ft}$ & $8.5 \mathrm{ft}$ \\
$L / D$ & 105 & 74 \\
\hline
\end{tabular}

3 , and the profiles are reported in Table 4. These profiles were determined across the tube radius furthest from the point of entry of the probe and were regularly checked for symmetry across the whole diameter. The e.m.f. generated by the probe thermocouple was opposed by a known reference voltage and the differential signal recorded on a high-gain potentiometric recorder. This procedure enabled an accurate point average temperature to be obtained from the observed temperature fluctuations.

The temperature at the wall, $T_{w}$, given in Table 4, was obtained by a least-squares fit of the profile in the vicinity of the wall to a secondorder polynomial, where the coefficient of the first-order term equals the expected slope at the wall, calculated from the wall heat flux.

Heat flux was determined from the electrical input, and the Reynolds number was calculated by a heat balance over the test section. These values agreed well with those obtained from the flow meters. The mixed-mean temperature was calculated from the equation

$$
T_{a v}=\frac{2}{u_{a v}} \int_{0}^{1} \frac{r}{R} u T \mathrm{~d}\left(\frac{r}{R}\right),
$$

using the measured temperature profile and the isothermal universal velocity distribution as given by Hinze [21]. The velocity profile, however, may be considerably distorted by free convection effects, as pointed out later, and in such cases the mean cup temperature reported in Table 3 will only be approximately correct. 
Table 3. Operating conditions

\begin{tabular}{|c|c|c|c|c|c|c|c|}
\hline \multirow{2}{*}{$\begin{array}{c}\text { Run } \\
\text { number }\end{array}$} & \multirow{2}{*}{$R e \times 10^{-3}$} & \multirow{2}{*}{$\operatorname{Pr}$} & \multirow{2}{*}{$\begin{array}{l}\text { Heat flux } \\
\left(\mathrm{Btu} / \mathrm{h} \mathrm{ft}^{2}\right)\end{array}$} & \multicolumn{3}{|c|}{$\begin{array}{c}\text { Temperature } \\
\left({ }^{\circ} \mathrm{F}\right)\end{array}$} & \multirow{2}{*}{$Z \times 10^{4}$} \\
\hline & & & & inlet & outlet & $\begin{array}{l}\text { mixed mean } \\
\text { at probe }\end{array}$ & \\
\hline \multicolumn{8}{|l|}{ Mercury } \\
\hline 1 & 3.8 & 0.021 & 430 & $59 \cdot 0$ & $123 \cdot 7$ & 117.9 & 1730 \\
\hline 2 & $4 \cdot 2$ & 0.021 & 340 & $74 \cdot 7$ & $122 \cdot 2$ & 118.7 & 1200 \\
\hline 3 & $5 \cdot 7$ & 0.021 & 670 & 60.5 & $129 \cdot 0$ & $123 \cdot 4$ & 1280 \\
\hline 4 & 83 & 0.021 & 940 & 60.2 & 125.9 & 119.8 & 820 \\
\hline 5 & $11 \cdot 4$ & 0.021 & 1020 & $71 \cdot 3$ & $122 \cdot 8$ & $119 \cdot 2$ & 490 \\
\hline 6 & $14 \cdot 7$ & 0.021 & 1230 & $79 \cdot 0$ & 127.8 & $124 \cdot 1$ & 350 \\
\hline 7 & 24.9 & 0.021 & 940 & 94.9 & $116 \cdot 4$ & $113 \cdot 1$ & 90 \\
\hline 8 & 29.6 & 0.021 & 2440 & 79.8 & 127.9 & 123.8 & 170 \\
\hline 9 & $43 \cdot 4$ & 0.022 & 2930 & $75 \cdot 3$ & 113.4 & $108 \cdot 2$ & 90 \\
\hline 10 & 95.5 & 0.021 & 3150 & 97.5 & $116 \cdot 4$ & 113.9 & 21 \\
\hline 11 & 124 & 0.021 & 3110 & $100 \cdot 4$ & 114.7 & 112.8 & 12 \\
\hline 12 & 172 & 0.021 & 5070 & $100 \cdot 1$ & $117 \cdot 1$ & 115.6 & 10 \\
\hline 13 & 251 & 0.021 & 6670 & 100.0 & $115 \cdot 2$ & $114 \cdot 1$ & 6 \\
\hline 14 & $10 \cdot 1$ & 0.018 & 1590 & $76 \cdot 9$ & $176 \cdot 1$ & $168 \cdot 8$ & 1030 \\
\hline 15 & $12 \cdot 1$ & 0.017 & 940 & $137 \cdot 3$ & 187.3 & $181 \cdot 6$ & 430 \\
\hline 16 & 21.8 & 0.017 & 2960 & $101 \cdot 5$ & 189.5 & 183.9 & 420 \\
\hline 17 & $22 \cdot 7$ & 0.017 & 2070 & $126 \cdot 5$ & 185.5 & 182.6 & 270 \\
\hline 18 & 27.8 & 0.017 & 1400 & $155 \cdot 2$ & 187.9 & $183 \cdot 7$ & 120 \\
\hline \multicolumn{8}{|l|}{$\mathrm{NaK}$ eutectic } \\
\hline 19 & 71.6 & 0.029 & 4610 & $84 \cdot 0$ & $90 \cdot 2$ & $89 \cdot 3$ & $0 \cdot 4$ \\
\hline 20 & $83 \cdot 3$ & 0.029 & 4610 & $84 \cdot 1$ & 89.5 & 88.7 & $0 \cdot 3$ \\
\hline 21 & 146 & 0.029 & 4610 & 85.5 & 88.6 & $88 \cdot 1$ & $0 \cdot 1$ \\
\hline 22 & $44 \cdot 0$ & 0.029 & 4610 & 83.8 & 94.0 & 92.5 & $1 \cdot 1$ \\
\hline 23 & 83.6 & 0.025 & 11400 & $113-3$ & 128.8 & 126.5 & 0.9 \\
\hline 24 & 31.4 & 0.023 & 12100 & $104 \cdot 1$ & 151.9 & 144.7 & 7.8 \\
\hline 25 & 153 & 0.020 & 12200 & 173.8 & 185.5 & 183.8 & 0.4 \\
\hline 26 & 97.2 & 0.020 & 12200 & $174 \cdot 6$ & $193 \cdot 0$ & $190 \cdot 3$ & $1 \cdot 1$ \\
\hline 27 & 71.9 & 0.019 & 12200 & $173 \cdot 0$ & 198.0 & $194 \cdot 3$ & 2.0 \\
\hline 28 & 39.5 & 0.019 & 12200 & $165 \cdot 4$ & $213 \cdot 6$ & $206 \cdot 4$ & $7 \cdot 3$ \\
\hline
\end{tabular}

\section{DISCUSSION OF RESULTS}

Temperature profiles may be readily compared by plotting them on the dimensionless basis $\left(T_{w}-T\right) /\left(T_{w}-T_{c}\right)$ vs. $y / R$. Typical profiles obtained in the present investigation together with those of other workers are shown in Fig. 3 for $R e \approx 10^{4}$, and in Figs. 4 and 5 for $R e \approx 4 \times 10^{4}$. It is apparent that large differences exist between profiles measured at the lower Reynolds number. While good agreement is found for the NaK profiles at $R e \approx 4 \times 10^{4}$ (Fig. 4), it may be seen from Fig. 5 that appreciable differences still exist at this Reynolds number for the measurements made in mercury. This general lack of agreement is characteristic of the published temperature profiles and has prevented the establishment of reliable values of the eddy diffusivity ratio.

A possible explanation for the discrepancies arises from the work of Yantovskii [22] who analysed mixed free and forced convection in turbulent flow and deduced that the free convection term in the flow equation would become significant when the group

$$
\mathrm{Y}=G r / R e^{2}(f / 2)
$$

was of the order of unity or greater. Applying this criterion to the profiles in Fig. 3 gives $Y$ values of 94, 64 and 7 for curves 1,2 and 3 respectively, thus indicating that free convection 


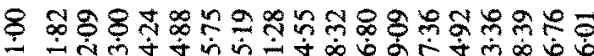

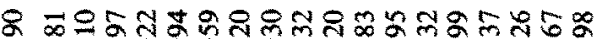

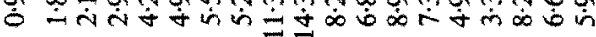

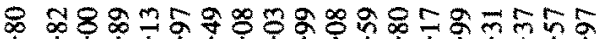

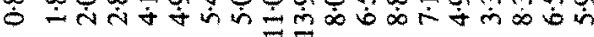

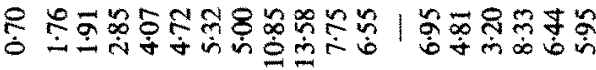

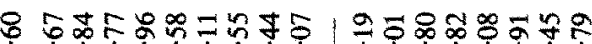

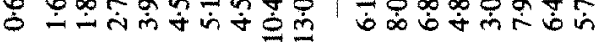
ํำลำ

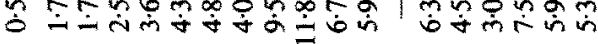

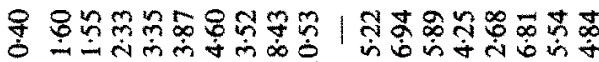

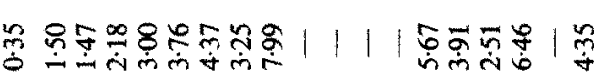

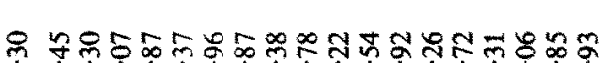

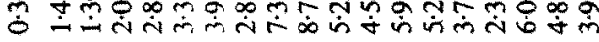
๙

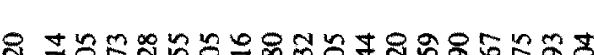

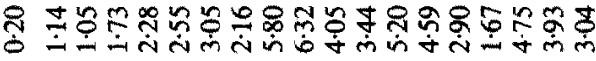

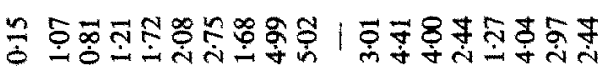

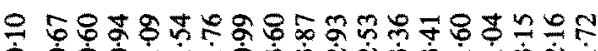

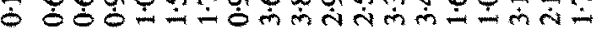

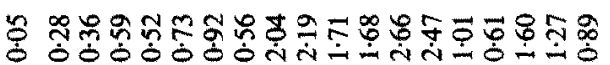

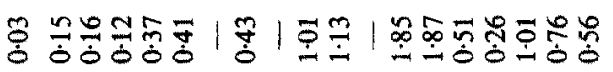

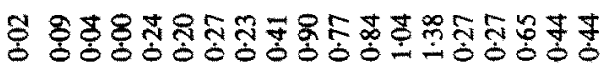

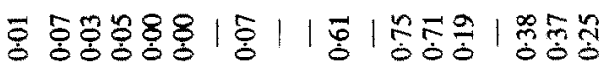
窟事 II

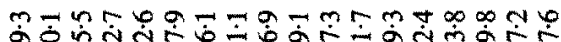

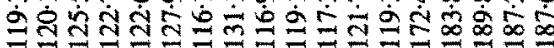

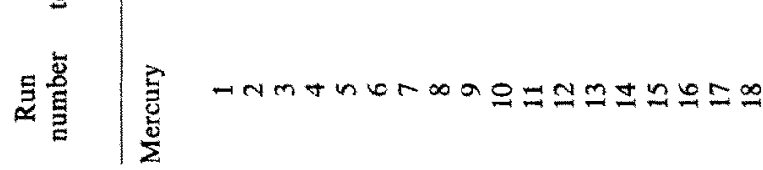

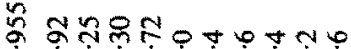

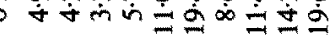

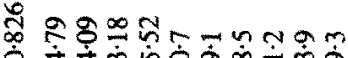

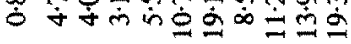

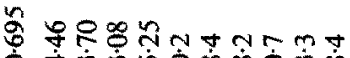

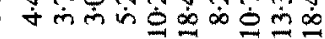

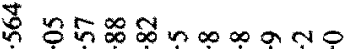

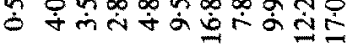

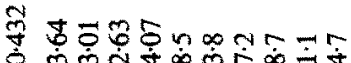

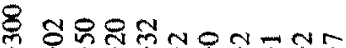

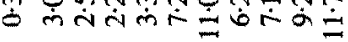

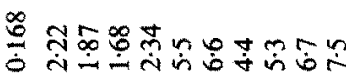

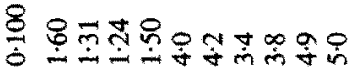

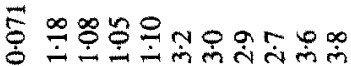

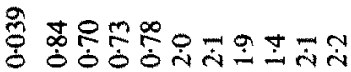

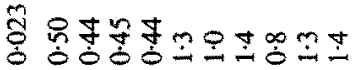

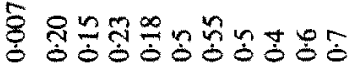
11:

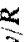
mmangenme

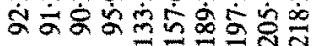


effects are present. Such effects would cause distortion of the velocity profile and would thus account for the differences observed in the temperature profiles. A free convection effect

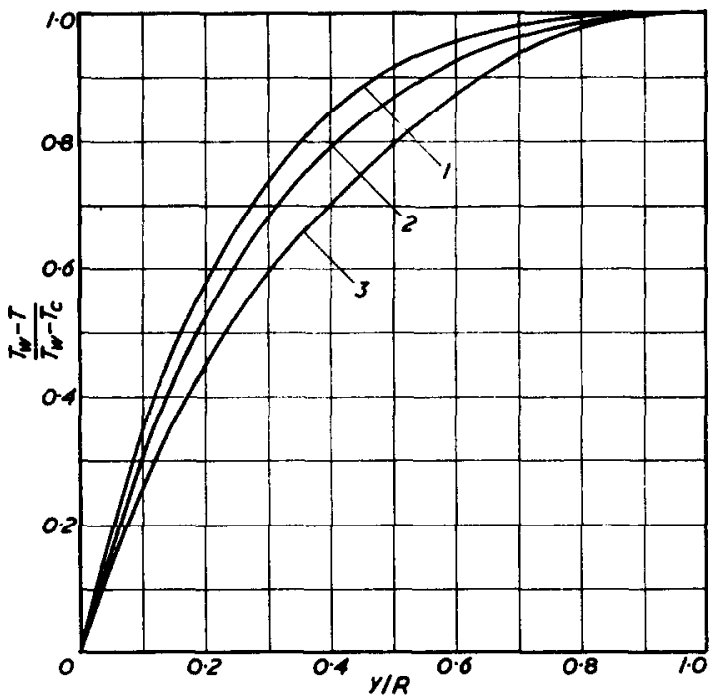

FIG. 3. Temperature profiles in mercury and NaK for $R_{e} \approx 10^{4}$.

1. Run No. $14 ; \operatorname{Re}=10100 ; \mathrm{Hg} ; Z=1030 \times 10^{-4}$

2. Run No. $5 ; R e=11400 ; \mathrm{Hg} ; Z=490 \times 10^{-4}$

3. Kirillov $[10] ; \operatorname{Re}=13700 ; \mathrm{NaK} ; Z=240 \times 10^{-4}$

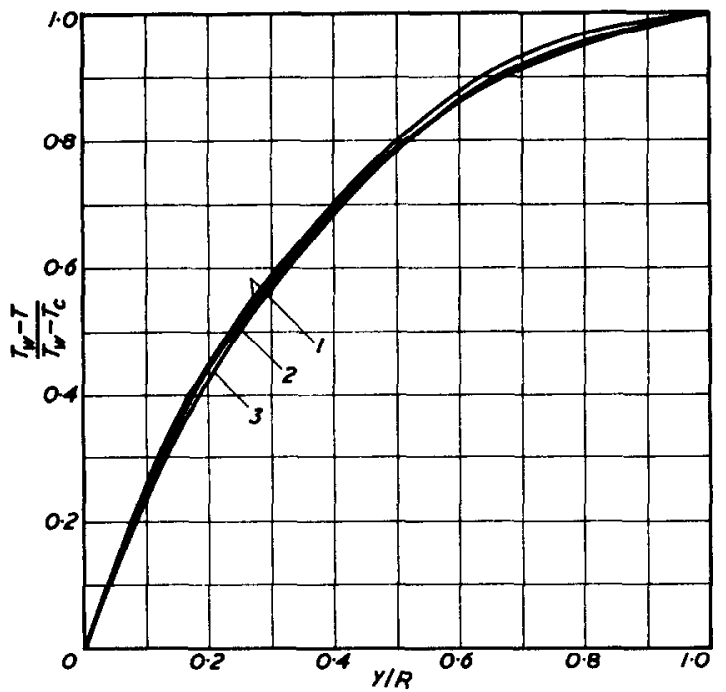

F1G. 4. Temperature profiles in NaK for $R e \approx 4 \times 10^{4}$.

1. Run No. $28 ; R e=39500 ; Z=7.3 \times 10^{-4}$

2. Run No. $22 ; R e=44000 ; Z=1.1 \times 10^{-4}$

3. Schrock [17]; $\operatorname{Re}=41400 ; Z=2.5 \times 10^{-4}$ would also exist for the mercury profiles of Fig. 5 where $Y=5$ and 18 for curves 1 and 2 respectively. For the NaK profiles of Fig. 4, on the other hand, the $Y$ values are $0 \cdot 11,0 \cdot 14$ and 0.9 and the absence of a free convection effect is confirmed by the excellent agreement of the curves.

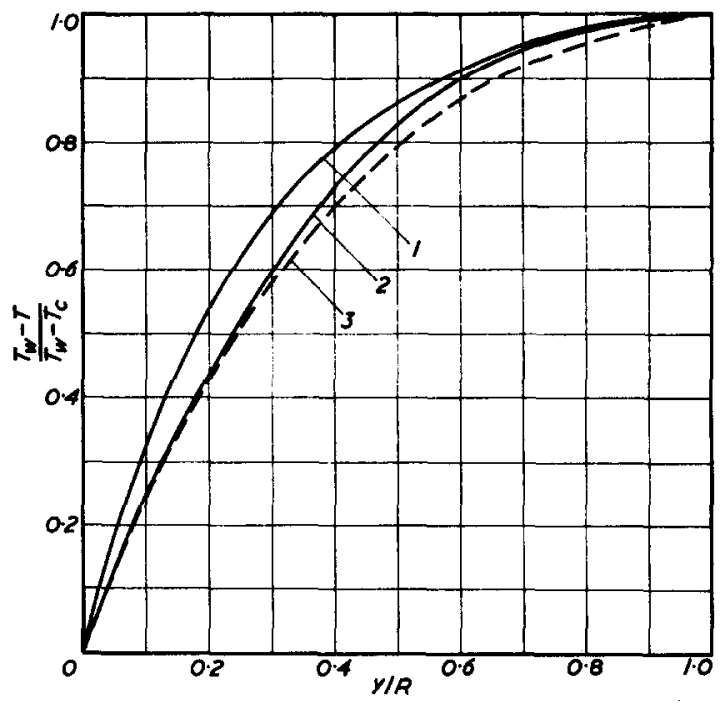

FIG. 5. Temperature profiles in mercury for $\operatorname{Re} \approx 4 \times 10^{4}$.

1. Subbotin [15]; $\operatorname{Re}=45500 ; \mathrm{Hg} ; Z=140 \times 10^{-4}$

2. Run No. $9 ; R e=43400 ; \mathrm{Hg} ; Z=90 \times 10^{-4}$

3. Average of $\mathrm{NaK}$ data of Fig. $4 ; Z<20 \times 10^{-4}$

Support for the presence of a superimposed free convection effect when $Y>1$ comes from the work of Schrock [17] with $\mathrm{NaK}$ in a horizontal tube, in which he found appreciable asymmetry of the temperature profile at $R e<10^{4}$ but no distortion at $R e>2 \times 10^{4}$, and values of the Yantovskii criterion for these two cases are $Y>2$ and $Y<0.2$ respectively.

\section{CORRELATION OF DATA}

In order to allow for the presence of superimposed free convection when comparing temperature profiles it is necessary that each curve should be identified by a suitable parameter showing the relative magnitude of the free convection effect. The Yantovskii criterion of 
equation (3) is a measure of this effect in turbulent flow but the present authors have found that it does not provide an orderly progression with the amount of distortion, when the results of different workers are considered. An alternative parameter,

$$
Z=\frac{R a}{R e} \cdot \frac{D}{L}
$$

is therefore proposed, as discussed below.

The correlating parameter, $Z$. In equation (4), the Rayleigh number $R a$, represents the product $G r^{*} \times P r$ where the Grashof number, $G r^{*}$, employs an "axial" temperature difference of the form

$$
\Delta T=(\mathrm{d} T / \mathrm{d} x) D,
$$

as first used by Hallman [23]. This axial temperature term, which is constant under conditions of constant heat flux, may be readily evaluated from inlet and outlet temperatures on the test section, and is related to the true radial temperature difference by a simple heat balance, so that

$$
(\mathrm{d} T / \mathrm{d} x) D=\frac{4 h}{G c_{p}}\left(T_{w}-T_{a v}\right) .
$$

From this equation it is clear that the mass flow rate, $G$, is implicit in the denominator of the Grashof number, $G r^{*}$, used here so that the form $G r / R e^{2}$ is retained in the parameter $Z$.

The effect of the $D / L$ ratio in correlations of combined free and forced convection is uncertain and the suitability of various powers of this ratio has been discussed by a number of workers $[24,25]$. In this investigation, use of the term $D / L$ to the first power was found to improve the orderliness of the correlation, and it was accordingly included in the definition of $Z$.

Values of $Z$. Table 3 shows values of $Z$ for the profiles reported here. $\mathrm{NaK}$ values are much smaller than those for mercury, mainly due to the large difference in density between these two fluids.
The curves of Figs. 3-5 have been labelled with the appropriate values of $Z$ and it is seen that the profiles become more convex as the relative free convection effect increases. For the undistorted profiles of Fig. 4, all the parameters are less than $20 \times 10^{-4}$ and this value of $Z$ corresponds to the limiting condition of $Y=1$, below which free convection effects are not significant. Values of $Z$ for the $\mathrm{NaK}$ profiles of Tables 3 and 4 are much lower than $20 \times 10^{-4}$ and therefore represent the condition of no profile distortion.

Form of correlation. The shape of the dimensionless temperature profile varies not only with the superimposed free convection effect, but also with the Reynolds number, and changes in the shape of the profile are best observed by plotting the dimensionless temperature, for selected radial positions, versus Reynolds number. The specific effect of free convection on the temperature profile will depend on whether the flow is upwards, downwards, or horizontal, and on whether the fluid is being heated or cooled. Table 1 shows that most of the available measurements are for heated upflow. A correlation has accordingly been drawn up for this flow condition and is given in Fig. 6 where the relevant profile data of the workers in Table 1 are plotted against Reynolds number for the radial positions $y / R=0.05,0 \cdot 10,0 \cdot 30,0.50$ and 0.70 , and data points have been labelled with the parameter $Z \times 10^{4}$.

The NaK data of the present authors were obtained in downward flow but, as mentioned above, these curves are undistorted by free convection so that the profiles will not be affected by the direction of flow; in the same way the profiles of Schrock [17] for Reynolds numbers above 20000 (for NaK horizontal flow) all have $Z<20 \times 10^{-4}$ and may also be considered unaffected by free convection. These two sets of profiles provide a convenient reference for the case of zero free convection and are therefore included in Fig. 6. These data are shown as solid points on the diagram, and $Z$ labels have been omitted in the interests 


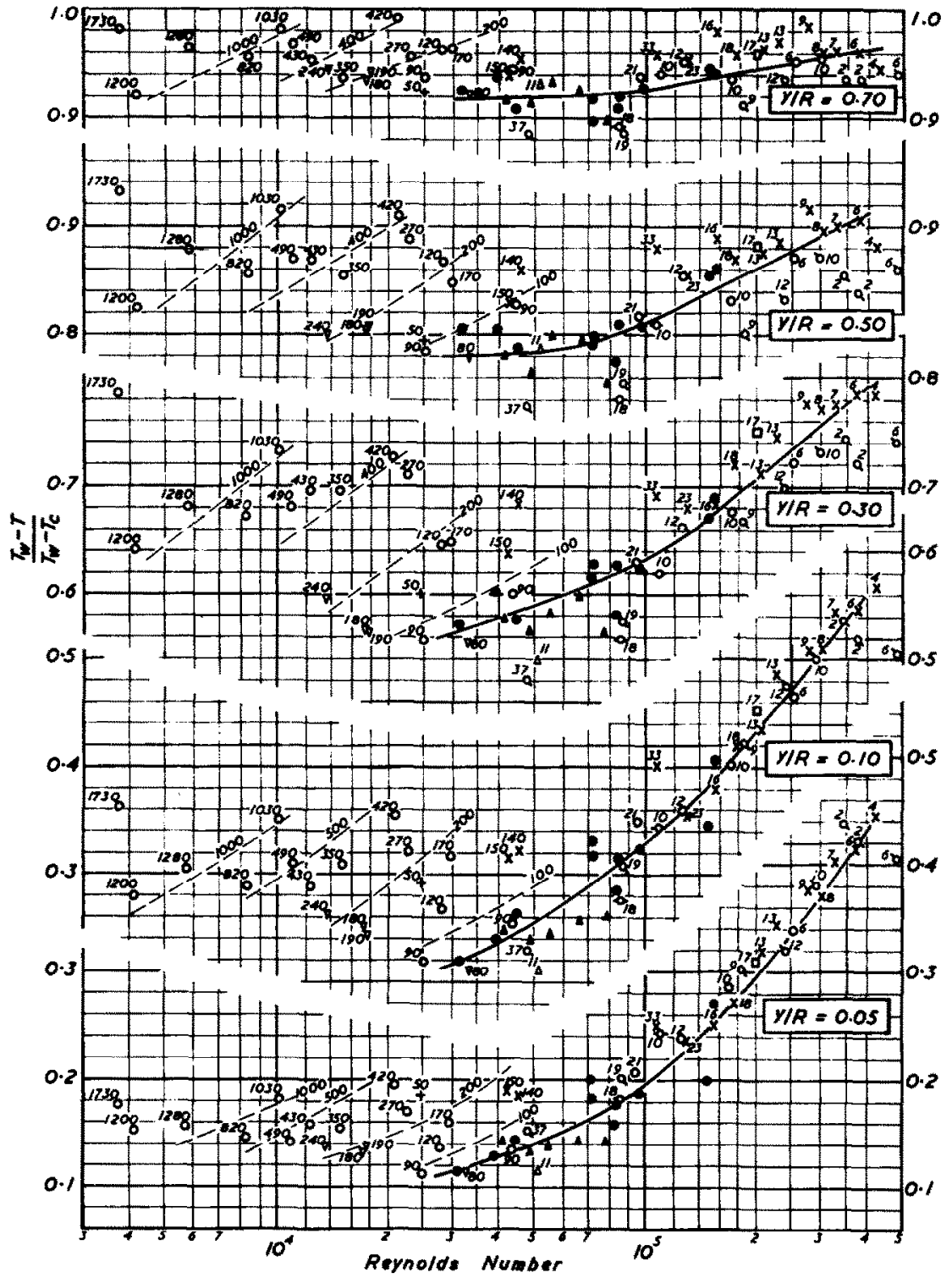

Fig. 6. Correlation of dimensionless temperature profiles.

Runs 1-18, $\mathrm{Hg}$,

Brown [9], $\mathrm{Hg}$,

$-\mathrm{O}$-Buyco [13], $\mathrm{Hg}$,

Q Isakof [8], $\mathrm{Hg}$,

Runs 19-28, NaK,

$\nabla$ Kirillov [10], NaK,

$\triangle$ Borishanskii [16], Na.

$\square$ Subbotin [12], $\mathrm{Hg}$,

$\times$ Subbotin [15], Hg,

+ Subbotin [12], NaK,

A Schrock [17], NaK,

The parameters shown are $Z \times 10^{4}$.

of clarity. Other data, which are not for upflow heating but which have been included in Fig. 6 on the basis that $Z$ is less than $20 \times 10^{-4}$, are three profiles of Brown et al. [9] for upflow cooling, and the horizontal flow data of Buyco [13] for $R e>80000$. 
It is evident from Fig. 6 that a large scatter exists in the available experimental data, particularly at lower Reynolds numbers. It is possible, however, to discern a trend in the data with $Z$, and this is tentatively indicated by the broken lines in the figure. While more experimental data are required for the exact effect of free convection to be predicted, it is clear that considerable distortion of the temperature profile may occur for Reynolds numbers as high as 50000 .

At higher Reynolds numbers $Z$ values are generally less than $20 \times 10^{-4}$, and it may be inferred that these profiles are unaffected by free convection. The solid lines in Fig. 6 have been drawn as the average of these data, with particular reference to the undistorted $\mathrm{NaK}$ points, so as to represent the limiting condition of no free convection.

\section{Undistorted temperature profiles}

The solid lines in the above correlation may be used to predict the shape of the temperature profiles which are not distorted by free convection. Such profiles are shown in Fig. 7 for the Reynolds number range $3 \times 10^{4}$ to $3 \times 10^{5}$.

\section{APPLICATIONS OF UNDISTORTED \\ TEMPERATURE PROFILES}

Evaluation of the ratio of eddy diffusivities and the Nusselt number from profile data requires both temperature and velocity profiles measured under the same conditions. Thus when a temperature profile is distorted by the presence of superimposed free convection, it is necessary to know also the form of the corresponding non-isothermal velocity profile. In the absence of such velocity data it is still possible to obtain correct values of $\epsilon_{H} / \epsilon_{M}$ and the Nusselt number by using the isothermal universal velocity distribution in conjunction with the undistorted temperature profiles of Fig. 7.

\section{Ratio of eddy diffusivities}

Values of this ratio are obtained by separate evaluation of the eddy diffusivities of heat and momentum.

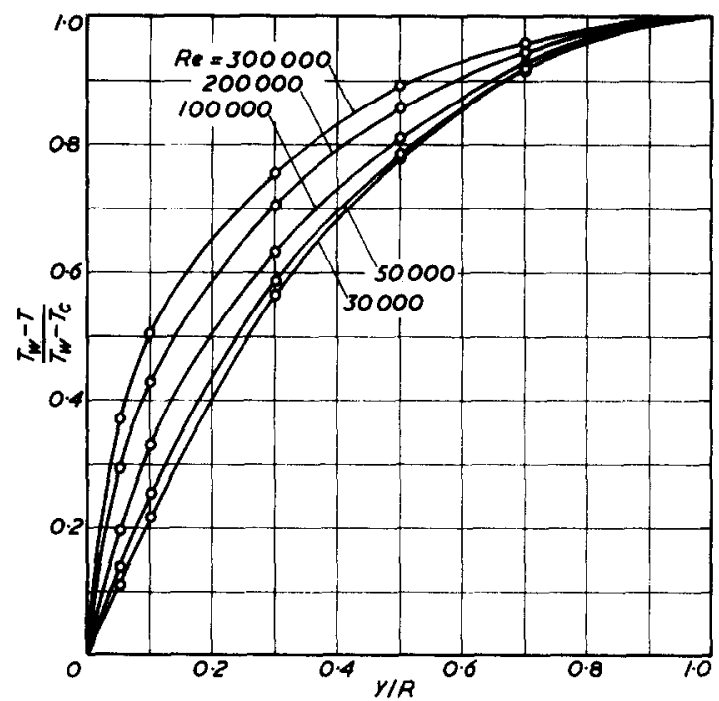

FIG. 7. Undistorted temperature profiles.

The eddy diffusivity of heat, $\epsilon_{\boldsymbol{H}}$. Temperature profile data may be used to calculate $\epsilon_{H}$ from the relationship

$$
\phi(y / R) q_{w} / \rho c_{p}=-\left(\alpha+\epsilon_{H}\right) \mathrm{d} T / \mathrm{d} y
$$

where $\phi(y / R)$ represents the heat flux distribution across the radius and, for constant heat flux, is given by

$$
\phi(y / R)=\frac{2}{(r / R) u_{a v}} \int_{0}^{r / R} u \cdot \frac{r}{R} \mathrm{~d}\left(\frac{r}{R}\right) .
$$

The heat flux at the wall is obtained from

$$
q_{w} / \rho c_{p}=-\alpha(\mathrm{d} T / \mathrm{d} y)_{0}
$$

and substitution into equation (7) gives

$$
\frac{\epsilon_{H}}{\alpha}=\frac{\phi(y / R)}{S_{y} / S_{0}}-1
$$

where $S_{y} / S_{0}$ is the ratio of the slope of the temperature profile at $y$ to the slope at the wall. Slopes were evaluated from the dimensionless temperature profiles of Fig. 7 as mid-point derivatives of a second-order regression on five points in the immediate vicinity of the point under consideration. The slope at the wall, 
$S_{0}$, was obtained by fitting a rational function of the form $y /(a y+b)$ to the data close to the wall, and values of $\phi(y / R)$ were computed by using the universal velocity distribution.

The eddy diffusivity of momentum, $\epsilon_{M}$. Numerous measurements have been made of turbulent velocity profiles in both air and water and the correct form of the resulting universal velocity distribution can be expected to hold for liquid metals also. Some very careful measurements have been made in water by Nikuradse [26] who presents the universal plot of $\epsilon_{M} / R u^{*}$ shown in Fig. 8. The values of $\epsilon_{M}$ for $y / R>0.5$ are very dependent on a precise knowledge of the slope of the velocity profile as the centre of the tube is approached and different forms of Fig. 8, incorporating approximately constant values of $\epsilon_{M} / R u^{*}$ have been proposed [17, 21]. Although a constant value of $\epsilon_{M}$ towards the centre of the tube is an attractive concept, the most comprehensive velocity measurements available in this region are those of Nikuradse, which result in the values of $\epsilon_{M}$ shown in Fig. 8 .

Values of $\epsilon_{H} / \epsilon_{M}$. The ratio of eddy diffusivities may now be calculated from the relation

$$
\frac{\epsilon_{H}}{\epsilon_{M}}=\frac{c_{H} / \alpha}{\epsilon_{M} / R u^{*}} \cdot \frac{2}{\operatorname{Re} \operatorname{Pr} \sqrt{ }(f / 2)}
$$

and these values are presented in Fig. 9, for a typical liquid metal Prandtl number of 0.02 . The values of $\epsilon_{H} / \epsilon_{M}$ increase from the wall to the tube centre and rise above unity for the higher Reynolds numbers. This latter effect contradicts the existing liquid metal heat-transfer theories, which do not allow for values of $\epsilon_{H} / \epsilon_{M}$ above $1 \cdot 0$.

At low Reynolds numbers, the values calculated for $R e=30000$, shown in broken lines in Fig. 9, are similar to those for $R e=50000$ and it appears that a lower limit is reached in the ratio of eddy diffusivities for $R e<50000$. Confirmation of this trend, however, must await extension of the zero distortion correlation of Fig. 6 to lower Reynolds numbers.
The Nusselt number

The average undistorted temperature profiles of Fig. 7 were used to calculate the Nusselt number (for constant heat flux) from the relation [20]

$$
N u=\frac{2 S_{0}}{\left(T_{w}-T_{a v}\right) /\left(T_{w}-T_{c}\right)} .
$$

The dimensionless average temperature was obtained by integrating the relevant form of equation (2), using the universal velocity distribution. Nusselt numbers are plotted against Péclet number, for $\operatorname{Pr}=0.02$, in Fig. 10. Also shown in the figure are the Martinelli-Lyon equation with $\psi=1$ and the same equation, allowing for variation of $\psi$. Values of $\psi$ were taken from Fig. 9 assuming that an average exists at $y / R$ approximately 0.25 , in common with the approximate radial location of the average velocity and average temperature. It may be seen that excellent agreement is obtained between the Nusselt numbers based on the temperature profiles, and those calculated from the Martinelli-Lyon equation using an average $\psi$.

Extension of the range of data in Fig. 10 again requires further experimental work for the prediction of undistorted temperature profiles at higher and lower Reynolds numbers.

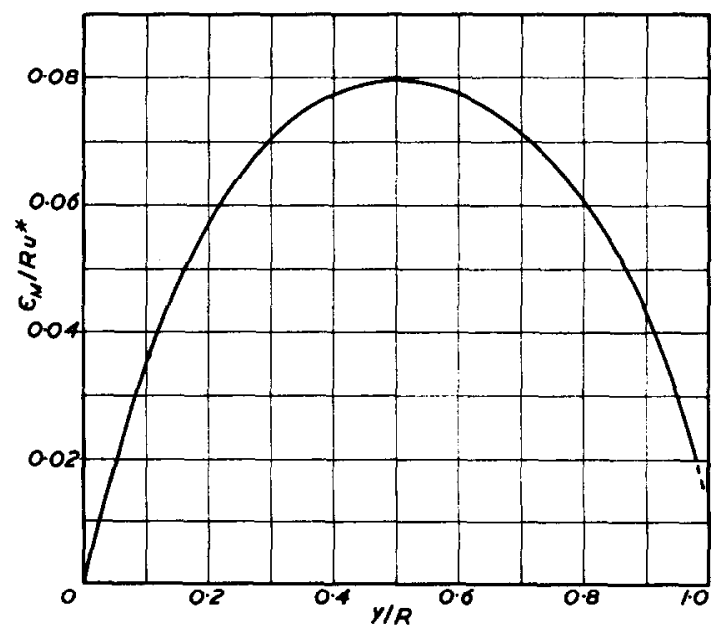

FIG. 8. The eddy diffusivity of momentum, Nikuradse [26]. 


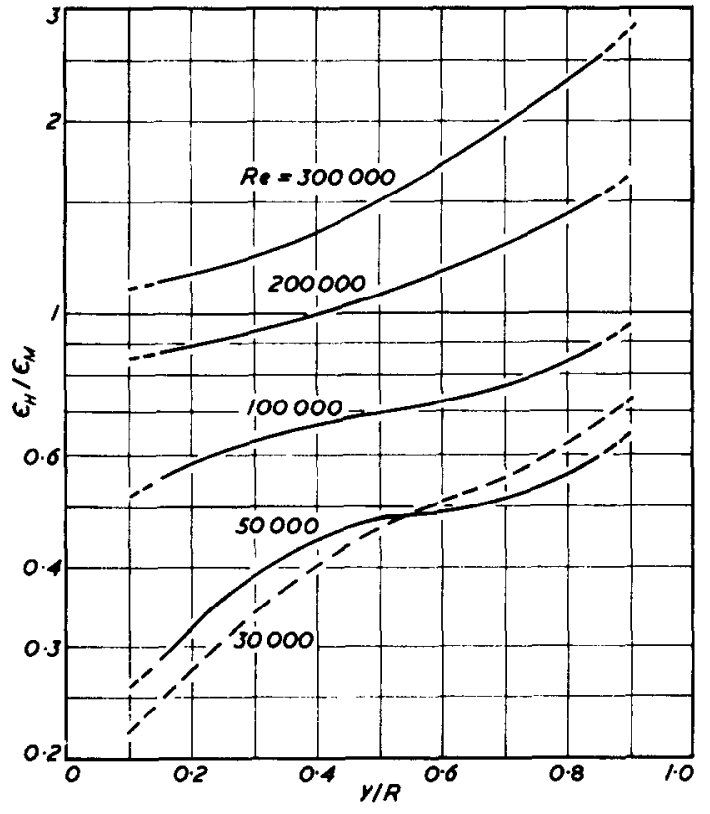

FIG. 9. Ratio of eddy diffusivities.

\section{CONCLUSIONS}

In liquid metals, particularly mercury, free convection may have a significant effect on the flow conditions for Reynolds numbers as high as 50000 , and the lack of agreement in published liquid metal temperature profiles may, in part, be attributed to this effect. The method of correlation presented in Fig. 6 allows assessment of the amount of distortion due to free convection.

Average undistorted temperature profiles may be obtained from the correlation and these give values of the eddy diffusivity ratio which exceed unity at high Reynolds numbers and therefore do not support the conclusions of the more recent heat-transfer theories. On the other hand, the agreement obtained between profile Nusselt numbers and those calculated from equation (1) using an average $\psi$, constitutes strong evidence for the validity of the Martinelli-Lyon analysis and the undistorted temperature profiles of Fig. 7.

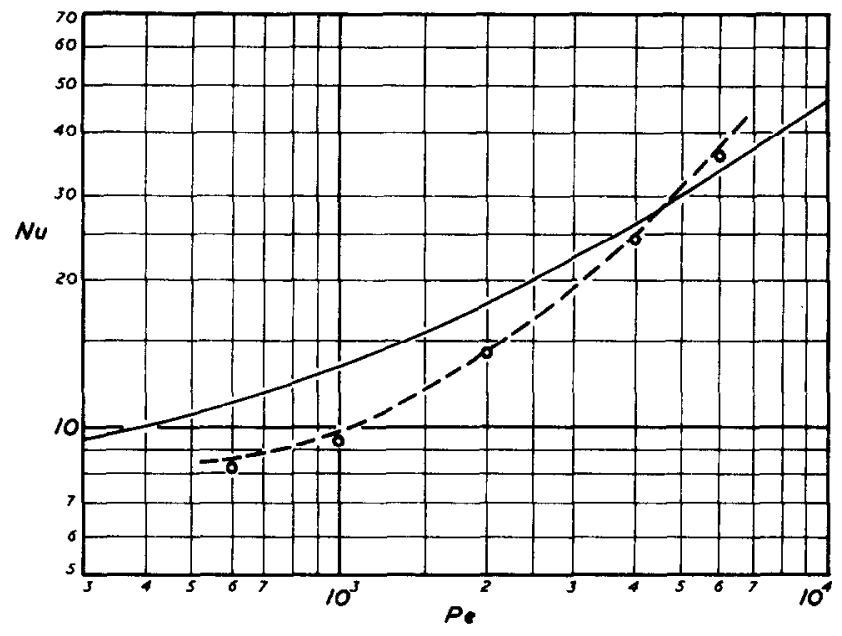

Fig. 10. Variation of Nusselt number with Péclet number.

cquation (1), $\psi=1$;

equation (1), $\psi$ taken from Fig. 9, at $y / R=0.25$.

$\bigcirc$ Nusselt numbers from undistorted profiles of Fig. 8. 


\section{REFERENCES}

1. R. C. Martinelul, Heat transfer to molten metals, Trans. Am. Soc. Mech. Engrs 69, 947-959 (1947).

2. R. N. LyON, Liquid metal heat transfer coefficients, Chem. Engng Prog. 47, 75-79 (1951).

3. B. Lubarsky and S. J. Kaufman, Review of experimental investigations of liquid-metal heat transfer, NACA R-1270 (1956).

4. W. C. MacDonald and R. C. Quittenton, A critical analysis of metal wetting and gas entrainment in heat transfer to molten metals, Chem. Engng Prog. Symp. Ser. 50(9), 59-67 (1954).

5. R. Jenkins, Variation of eddy conductivity with Prandtl modulus and its use in prediction of turbulent heat transfer coefficients, in Proc. Heat Transf. Fluid Mech. Inst., pp. 147-158. Stanford University Press, Stanford (1951).

6. R. G. DeissLer, Analysis of fully developed turbulent heat transfer at low Péclet numbers in smooth tubes with application to liquid metals, NACA RM E52F05 (1952).

7. N. Z. AZER and B. T. CHAO, A mechanism of turbulent heat transfer in liquid metals, Int. J. Heat Mass Transfer 1, 121-138 (1960).

8. S. E. IsAKOFF, Heat and momentum transfer in turbulent flow of mercury, Ph.D. Dissertation, Columbia University (1952).

9. H. E. Brown, B. H. Amstead and B. E. Short, Temperature and velocity distribution and transfer of heat in a liquid metal, Trans. Am. Soc. Mech. Engrs 79, 279-285 (1957).

10. P. L. Kirillov, V. I. Surrotin, M. Y. Suvorov and M. F. Troyanov, Heat transfer in a tube to sodium-potassium alloy and to mercury, Soviet J. Atom. Energy 6, 253-260 (1960).

11. V. I. Subbotin, M. K. Ibragimov, M. N. Ivanovskil, M. N. ARnoldov and E. V. Nomofilov, Turbulent heat transfer in a stream of molten metais, Soviet $J$. Atom. Energy 10, 373-376 (1962).

12. V. I. Subbotin, M. K. Ibragimov, M. N. Ivanovskit, M. N. ARnoldov and E. V. Nomofilov, Heat transfer from the turbulent flow of liquid metals in tubes,
Soviet J. Atom. Energy 11, 769-774 (1962).

13. E. H. BUYCO, Heat and momentum transfer in liquid metals, Ph.D. Dissertation, Purdue University (1961).

14. L. S. KoKOREV and V. N. Ryaposov, Turbulent heat transfer during the flow of a heating medium of small Prandtl number along a tube, Int. Chem. Engng 2, 514-519 (1962).

15. V. I. Subbotin, M. K. Ibragimov and E. V. Nomofilov, Measurements of temperature fields for turbulent flow of mercury in a tube, Teploenergetika 10(6), 70-74 (1963). (U.K.A.E.A. Translation 658).

16. V. M. BorishanSKiI, T. V. ZABlotSKayA and N. I. IVASHCHENKO, Heat transfer to molten metals during flow in pipes, Soviet J. Atom. Energy 14, 318-320 (1964).

17. S. L. Schrock, Eddy diffusivity ratios in liquid metals, Ph.D. Dissertation, Purdue University (1964).

18. A. D. CARR and R. E. BALZHISER, Temperature profiles and eddy diffusivities in liquid metals, Br. Chem. Engng 12, 53-57 (1967).

19. A. D. CARR and H. O. BuHR, Liquid metal heat transfer loops, S. Afr. Mech. Engr 16, 1-7 (1966).

20. H. O. BuHR, Heat transfer to liquid metals, Ph.D. Dissertation, University of Cape Town (1967).

21. J. O. HinzE, Turbulence, pp. 517-525. McGraw-Hill, New York (1959)

22. E. I. YANTOVSKII, An estimate of the influence of free convection upon turbulent flow, Soviet Phys.-Tech. Phys. 4, 1280-1282 (1960).

23. T. M. Hallman, Combined forced and free-laminar heat transfer in vertical tubes with uniform internal heat generation, Trans. Am. Soc. Mech. Engrs 78, 1831-1841 (1956).

24. F. J. Bayley, P. A. Milne and D. E. Stoddart, Heat transfer by free convection in a liquid metal, Proc. R. Soc. 265A, 97-108 (1961).

25. B. Metais and E. R. G. Eckert, Forced, mixed and free convection regimes, J. Heat Transfer 86, 295-296 (1964).

26. J. Nikuradse, Gesetzmässigkeiten der turbulenten strömung in glatten rohren, ForschHft. Ver. Dt. Ing. 356 (1932).

Résumé-Des profils de température mesurés dans le mercure et l'eutectique $\mathrm{NaK}$ sont présentés pour un écoulement vertical dans des tuyaux dans les conditions d'un flux de chaleur constant et l'on montre que les profils dans le mercure sont déformés par l'effet de la convection naturelle qui se superposent à la convection forcée jusqu'à des nombres de Reynolds d'au moins 50000. On présente une corrélation par laquelle la quantité de distorsion sous des conditions données peut être estimée, et la forme du profil de température sans distorsion peut être prévue. Ces profils sont employés pour déterminer le rapport des diffusivités turbulentes et le nombre de Nusselt pour les métaux liquides dans la gamme des nombres de Reynolds de $3 \times 10^{4} \mathrm{à} 3 \times 10^{5}$.

Zusammenfassung - Es werden die Temperaturprofile in Quecksilber und dem Etektikum NaK beschrieben, die für senkrechte Strömung in Rohren und konstanter Heizflächenbelastung gemessen wurden. Es zeigt sich, dass die Profile in Quecksilber durch die Überlagerung freier Konvektion gestört sind, und zwar bis zu Reynolds-Zahlen von wenigstens 50000. Es wird eine Gleichung angegeben, an Hand der die Grösse der Störung bei gegebenen Bedingungen abgeschätzt und der Verlauf des ungestörten Temperaturprofiles berechnet werden kann. Diese Profile werden benützt, um den turbulenten Austauschgrad und die Nusselt-Zahl der flüssigen Metalle für Reynolds-Zahlen von $3 \times 10^{4}$ bis $3 \times 10^{5}$ zu bestimmen. 
Аннотация-Измерены профили температур в ртути и в эвтектике $\mathrm{Hg}$ и $\mathrm{NaK}$ при вертикальном течении в трубах в условиях постоянного теплового потока. Показано, что поля температур в ртути исканаются под влиянием конвекции в диапавоне чисел Рейнольдса вплоть до 50000 . Приводится уравнение, с помощью которого можно рассчитать величину искажения при данных условиях и форму неискаженного температурного профиля. Эти профили используются для определения отношения коәффициента вихревой диффузии к числу Нуссельта для жидких металлов в диапазоне чисел Рейнольдса от $3 \times 10^{4}$ до $3 \times 10^{5}$. 